\title{
Blockchain Smart Contracts on IOT
}

\author{
E. Kanimozhi, D. Akila
}

\begin{abstract}
Blockchain smart contracts are PC programs that can be adequately executed by an arrangement of ordinarily questioning center points, without the need of an external trusted in power. Since shrewd contracts handle and trade assets of huge regard, other than their correct execution it is also imperative that their use is secure against ambushes which go for taking or modifying the favorable circumstances. Ethereum, the most eminent and used structure for sharp contracts up to this point. It analyze the security vulnerabilities of Ethereum smart contracts, giving a logical order of customary programming traps which may incite vulnerabilities and exhibit a movement of attacks which misuse these vulnerabilities, empowering a foe to take money or cause other mischief.
\end{abstract}

Keywords--- Blockchain, Ethereum, Internet of Things,

\section{INTRODUCTION}

Blockchain as the word alludes implies a chain of Blocks. Blockchain implies having various squares fastened together and each square stores exchanges such that it is absurd to expect to change these exchanges. A Blockchain is a connected rundown of records, called obstructs, with each square being anchored by means of encryption. It was originally developed as a major aspect of the Bitcoin digital money all together to maintain a budgetary freely unquestionable record. The Blockchain can be thought of as a singleton state-machine that can change between states through cryptographically-anchored exchanges.

Blockchain one of a kind is the manner in which these segments work and associate with one another. A portion of the critical Ethereum segments are Ethereum virtual machine, Miner, Blocks, Transactions, Consensus calculation, Accounts, Smart contracts, mining hubs, Ether and Gas.

A Blockchain is the structure of data that addresses a cash related record entry, or a record of a trade. Each trade done cautiously set apart to ensure its validity and that no one can changes it, so it record itself and its present trades inside it are believed to be of high uprightness. The Blockchain is a mixed, flowed database that records data, or in that capacity it is an automated record of any trades, contracts - that ought to be independently recorded. One of the key features of Blockchain is this electronic record is accessible over a couple a colossal number of PC and will without a doubt be kept in a single place [1].

Blockchain can be actualized through P2P n/w, Cryptography, Digital marks, Nodes, Hashing, Consensus conventions, Byzantine Fault Tolerance, Proof of Stake,

Manuscript received September 16, 2019.

E. Kanimozhi, Ph.D. Research Scholar, Department of Computer Science, School of Computing Sciences, Vels Institute of Science, Technology \& Advanced Studies (VISTAS), Chennai, India. (e-mail: kanimozhi135@gmail.com)

Dr.D. Akila, Associate Professor, Department of Information Technology, School of Computing Sciences, Vels Institute of Science, Technology \& Advanced Studies (VISTAS), Chennai, India. (e-mail: akiindia@yahoo.com) Assention Convention.

Delegated Proof of Stake (DPoS),Proof of Work and Mining.

In a P2P organize, the customer uses and gives the foundation of the framework meanwhile, in spite of the way that giving the benefits is totally purposeful. Every companion (a "peer" being a PC structure on the framework) is seen as proportional and are by and large implied as centers A friend makes a bit of figuring assets, for example, circle collecting, managing force or system data trade limit, plainly accessible to different people denied of the stipulation for any focal coordination by servers or firm has.

Indeed, even with each center point being identical, through going up against various occupations by the blockchain [1]bionetwork, for instance, inspite of an excavator or a "full core interest". By restraint of a full center, the whole blockchain is copied onto a lone device, while the contraption is associated with the framework. This gathers the informational index away on a blockchain can't be lost or squashed in light of the path that to do everything considered would mean pounding every single full spotlight point on the framework. Thusly, up to a singular center point with a copy of a blockchain exists; most of the records will remain immaculate, giving the probability to change that arrange.

Cryptography is the strategy for camouflaging and uncovering, also called scrambling and unscrambling, data through complex arithmetic. This implies the data must be seen by the proposed beneficiaries and no one else. The strategy includes taking decoded information, for example, a bit of content, and encoding it utilizing a numerical calculation, known as a figure. It makes a cipher text, a touch of data that is completely vain and silly until the minute that it is unscrambled. This method for encryption is known as symmetric-key cryptography.

Motorized etchings were one of the central parts of worthing the security and uprightness of the data that is recorded onto a blockchain. They are a standard bit of most blockchain traditions, in a general sense used for verifies trades and squares of trades, trades of checked information, programming scattering, get the board and whatever unmistakable conditions . where perceiving and keeping any outer altering is essential. Propelled marks utilize uneven cryptography, inferring that information can be bestowed to anyone, utilizing an open key.

An inside point can be any special electronic contraption, including a PC, telephone or even a printer, as long as it is associated with the web and in that limit has an IP address. The action of a middle point is to help the system by keeping up a duplicate of a blockchain and, from time to time, to process exchanges. Focus focuses are as frequently as conceivable composed in the structure of trees, known as coordinated trees. 
Each propelled money has its very own unique focus focuses, keeping up the exchange records of that specific token. Hubs are the individual parts of the greater data structure that is a blockchain. As the owners of centers promptly contribute their enlisting resources for store and endorse trades they inspire the chance to assemble the trade charges and procure a reward in the fundamental advanced cash for doing in that capacity. This is known as mining or molding.

Blockchain accord conventions are what keep every one of the hubs on a system synchronized with one another, As a term, 'assention' suggests that the centers on the framework surrender to a comparative state of a blockchain, it could be said making it a self-looking into organic framework. This is a completely essential bit of the improvement, completing two key cutoff points. Straightforwardly off the bat, accord customs permit a blockchain to be restored, while guaranteeing that each square in the chain is genuine correspondingly as keeping people made a difference. Moreover, it shields any single segment from controlling or annihilating the entire blockchain structure. The motivation behind assention rules is to ensure a particular chain is utilized and looked for after.

Accord rules are a specific course of action of rules that center points on the framework will ensure a square seeks after while affirming that square and the trades inside it. The key need to achieve an agreement is a steady affirmation between center points on the framework for a lone data regard, even if there should arise an occurrence of a bit of the centers failing or being dishonest in any way.

Accord conventions are intended to be hard to mimic or imitate by being amazingly exorbitant to do, as far as time, the processing assets required or the possessions of a specific digital currency. The strategies for agreement shift contingent upon the blockchain inside which they are approving the squares and there exist an assortment of types of accord, with a reliable progressing banter about what is the best and effective technique.

Assention conventions are a key point in permitting a blockchain to restrain and exist. Everything considered, as at its center a blockchain is a record of data it is pivotal that there is prevalent assertion that the data that is being verified is clear and accurate.

The "Byzantine Generals' Problem" expresses that no two PCs on a decentralized system can altogether and obviously ensure that they are showing similar information. Expecting the system is inconsistent, they can never make sure that the information that they conveyed has arrived. At its center, the Byzantine Generals' Problem is accomplishing an agreement over an appropriated system of gadgets, some of which could be possibly flawed, while additionally being tired of any aggressors endeavoring to undermine the system.

Confirmation of stake is the agreement calculation utilized by digital currencies to approve squares. The framework was at first proposed in year 2011 and the principal digital currency for actualize how toPeer coin in 2012. The fundamental favorable circumstances of evidence of stake are vitality productivity and security.

In a proof of stake framework, the maker of the going with square is controlled through randomized structure (i.e) to a compelled degree, managed by the proportion of that

cryptographic money a client is holding or, every so often, to what degree they have been holding that specific cash. Instead of computational impact, equivalent for the case in affirmation of work, the likelihood of making a square and getting the related prizes is contrasting with a client's holding of the underlining token or electronic money on the system.

Appointed Proof of Stake (also called DPoS) is an accord calculation keeping up verifiable concurrence on reality over the system, approving exchanges and going about as a type of computerized majority rule government. It is the convention of decision at Lisk and in light of current circumstances.

Allotted check of stake uses nonstop throwing a poll joined with a social game plan of reputation to achieve assention. It might be accepted to be the least thought accord tradition appeared differently in relation to all others as it is the most comprehensive. Each token holder can practice an element of impact about what occurs on the structure

Dynamic administrators are tossed a survey into their occupations by token holders. The tossing a ticket control that the token holder has, furthermore called tossing a vote weight, is coordinated by what number of the base token the record is holding. It is principal that the operators are picked with the best energy of the structure on a basic measurement as they keep the system running adequately and securely. In some DPoS modifications, a representative needs to show commitment by saving his advantages into a period slung security account (which is appropriated if there should rise an occasion of pernicious lead). This alteration of DPoS is from time to time suggested as store based confirmation of stake.

Check of work (contracted to POW) is an understanding custom presented by Bitcoin and utilized thoroughly by different various propelled sorts of money. This technique is implied as mining and everything considered the middle focuses on the structure are known as "excavators". The "affirmation of work" comes as a response to a sensible issue, one that requires vital work to get together at, yet is reasonably checked to be right once the fitting response has been come to.

The best way to deal with light up this sensible request is through focus focuses on the structure, running a long and optional procedure of appearing on an experimentation premise. Frankly, this recommends the issue could be cleared up on first endeavor, paying little heed to the manner in which this is fantastical, to the point where it is in each down to earth sense unfathomable. The best possible response should be a lower number than the hash of the square for it to be perceived, known as the 'objective hash'

\section{SMART CONTRACTS}

A smart contract is a PC code running over a blockchain containing a lot of principles under which the gatherings to that keen contract consent to associate with one another. In the event that and when the pre-characterized rules are met, the understanding is consequently upheld. 
The shrewd contract code encourages, confirms, and authorizes the arrangement or execution of an understanding or exchange. It is the easiest type of decentralized mechanization.

It is a component including computerized resources and at least two gatherings, where a few or the majority of the gatherings store resources into the brilliant contract and the benefits naturally get redistributed among those gatherings as indicated by an equation dependent on specific information, which isn't known at the season of agreement inception. Smart contracts are Self-checking, Self-executing, Alter safe, smart contracts can transform legitimate commitments into mechanized procedures, Certification a more noteworthy level of security, Diminish dependence on confided in middle people.

\section{HASHING}

Hashing is like a unique mark. Hashing is the route toward changing string data into another settled length string data and it is preposterous to re-deliver or perceive the primary data from resultant string data. Hashing ensures that even a slight change in data will thoroughly change the yield data and no one can discover the modification in the principal data. There is another basic property of hashing is that paying little respect to the range of data string data the length of its yield is continually settled. For example, using SHA256 hashing figuring and limit with any length of data will reliably make 256-piece yield data. This can especially end up significant when enormous proportion of data can be secured as 256-piece yield data. Ethereum uses Hashing broadly. It hashes all the trade data, hashes different trade hashes to make single root trade hash and in fact the squares in Ethereum are in like manner addressed as hash. Hash types: Message digest Algorithm (MD5), Secure Hash Algorithm (SHA-1).

Hashing in Blockchain

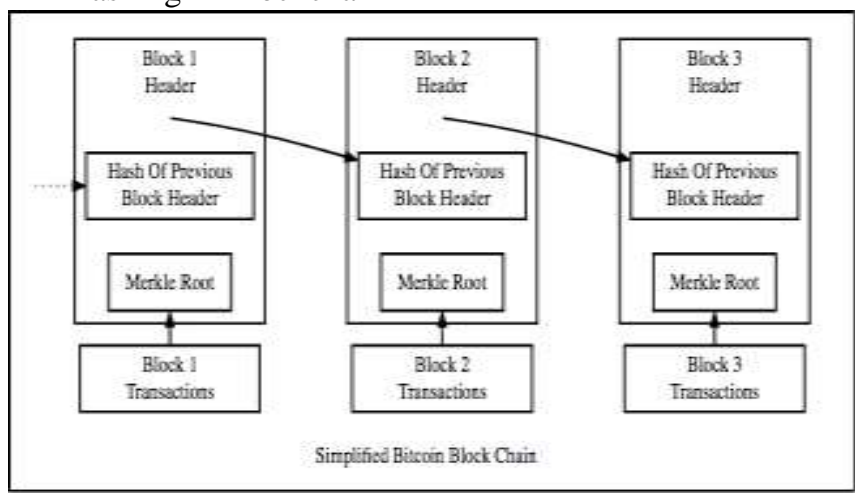

Fig. 1: Hashing in Blockchain

A hash pointer is like a pointer, however rather than simply containing the location of the past square it additionally contains the hash of the information inside the past square. This one little change is the thing that makes blockchain so incredibly dependable and trailblazing

\section{INTERNET OF THINGS}

It is the arrangement of device that appears strange or unnecessarily complicated, for instance, vehicles, and home machines that contain devices, programming, actuators, and accessibility what empowers these things to interface, convey and exchange data. IoT improves growing Internet organize past standard device, for instance, work zones, workstations, mobile device and tablets, to any extent of generally doltish or non-web engaged physical devices and conventional things. Embedded with development, these strange devices can pass on and relate over the Internet, and they can be remotely checked and controlled.

\section{DISCUSSION \& RESULTS}

Another system is proposed for anchoring a blockchain applied to contracts the executives, for example, advanced rights management. This component incorporates another Consensus technique utilizing believability score and makes a mixture blockchain by on the other hand utilizing this new strategy and verification of-stake[2]. On account of the web ,which isn't relied upon to give insightful development in the traditional grouping and number of contraptions related with the web ,which isn't relied on to give high accessibility, constant information delivery, scalability, security, resilience, and low torpidity[3] .To address these issues, in this paper proposes a novel blockchain based scattered cloud orchestrating with a thing de-ned networking(SDN) interface with controller absence of definition focus fixations at the edge of the structure to satisfy the required technique rules.

This paper presents a portion of the related segments inside the multi faced arrangement creating towards quickening the usefulness of blockchain-empowered administrations through dispersed adaptability and specialist based automation. Hash calculation (SHA) family might be utilized, for example, events in the SHA-3 subset, RACE integrity Primitives Evaluation Message Digest (RIPEMD) family and in the families reliant on Zemor-tillitech hash work or on Knapsack-based hash limits [4]. What's more, the structure of a blockchain related section which adaptively and securely keeps up customer security tendencies for IOT devices in the blockchain mastermind .Individual security spillage can be checked in light of the way that the door effectively shields customer's fragile data from being gotten to without their consent. An amazing propelled check framework is proposed for the reason $s$ of affirmation and secure organization of insurance tendencies.

The E-closeout ,one of the prominent online business exercises enables bidders to straightforwardly offer the items over the internet[5].In this paper gives an E-sell off instrument dependent on blockchain to guarantee electronic seals confidentiality, on repudiation, and un-changeability in under - advanced brilliant contracts may cost more cash hand important ,it just records 7 -enemies of examples and the location strategy for 3 of them .In this paper Frist top to bottom examination on such under - enhanced keen contracts. They structure Gas Reducer the main apparatus to consequently identify all these enemies of examples by the byte code of smart contracts and supplant them with effective code where bytecode to bytecode improvement utilizing gas reducer to break down every savvy contract and 
their execution follows, we distinguish 9,490,768 and $557,565,754$ enemy of example occasions in conveying summoning shrewd contracts.[6]

This paper proposes a novel tradition hoping to execute splendid contracts as an element of a blockchain exchange endorsement. With NECTAR took care of and successfully handled the issue of improving the security, precision and undeniable status of sharp gets that are executed as an element of exchange endorsement on the blockchain. Evidences of right executions are then fused into blockchain transactions[7]. The creating IOT is going up against basic flexibility and secure challenges .Of two one hand, IOT devices are "fragile" \& require outer help . Corner figuring ensures bearing watching out for the insufficiency of bound together appropriated registering in scaling immense number contraptions. On other hand, IOT contraptions are "powerless" standing up to poisonous software engineers as a result of benefit goals. This paper, it examines to address the challenges an edge-IOT framework named "Edge Chain" in perspective of blockchain smart contracts. Edge Chain facilitates a permissioned blockchain to interface the edge cloud resources[8]. This paper chips away at Vegvivir a fragment condition blockchain for use in power-obliged IoT conditions with confined framework accessibility. It is a permissioned, composed non-cyclic graph(DAG) sorted out square chain that can be used to make a typical, cautiously structured data document that screens data provenance.[9]

In a blockchain IoT condition, when information or gadget confirmation data is put on a square chain, individual data might be spilled through the verification of-work process or address seek. This paper discuss the apply ZeroKnowledge confirmation to a keen meter framework to prover without uncovering data, for example, open key, and we have contemplated how to upgrade namelessness of square chain for security assurance[10].As of late, decentralized (on-blockchain) stages have risen to supplement brought together (off-blockchain) stages for the execution of computerized, advanced ("brilliant") contracts. In any case, neither one of the alternatives can independently fulfill the necessities of an expansive class of uses. On-blockchain stages experience the ill effects of versatility, execution, exchange costs and different impediments. Off-blockchain stages are distressed by downsides because of their reliance on single confided in outsiders. We contend that in a few application zones, half and half stages made from the combination out of on-and off-blockchain stages are progressively ready to help savvy gets that convey the ideal nature of administration (QoS). Half breed designs are to a great extent unexplored. The point of this paper has been to contend that there are valid justifications to consider half and half models made out of now and again blockchain segments as options for the execution of brilliant contracts with strict QoS prerequisites. As a proof of idea, we have shown that half breed structures are implementable as long as the off-block chain part furnishes standard APIs to speak with the standard APIs that current blockchain offer.[11]

By and extensive, a Certified Authorization (CA) is required to sign, control, check and deny open key affirmations. Assorted CAs together shapes the CA-based Public Key Infrastructure (PKI). The use of a PKI drives one to put trust in the CAs, which have wound up being a particular point - of-disappointment on different events. Square chain has climbed as a transformational improvement that replaces joined confided in untouchables with a decentralized, uninhibitedly certain, peer-topper information store which keeps up information reliability among focus fixations through different accord customs. this paper, pass on three square chain-based decisions instead of the CA-based PKI for supporting IoT contraptions, in light of Emersion Name Value Service (NVS), sharp specialists by Ethereum square chain, and Ethereum Light Sync client[12].

Sharing economy stages, for example, Airbnb have as of late thrived in the travel industry. Notwithstanding, depending on an incorporated outsider sharing stage definitely prompts single purpose of shortcoming, higher expenses, absence of trust and administration issues for the two clients and specialist co-ops . In addition, sharing any IoT-gadgets empowered savvy house represents a genuine danger to client's security. This paper discuss how to investigate the security concerns related with authoritative leasing or renting of IoT gadgets empowered home. We propose a technique to wipe out protection dangers from IoT-empowered telematics gadgets in a savvy home by means of blockchain-based shrewd contract. With the end goal of outline, we center around how we can go around the security risk from indoor observation IP cameras in a shrewd home sharing economy.[13][16].

This paper breaks down a basic access control issue in the Internet of Things (IoT). Specifically, we envision a sharp contract-based structure, which contains explicit access control contracts (ACCs), one judge contract (JC) and one select contract (RC), to accomplish scattered and dependable access control for IoT frameworks. Every ACC gives one access control framework to a subject-object set, and executes both static access rights ensuring dependent on predefined approachs and dynamic access right help by checking the lead of the subject. The JC fathoms a horrible direct sentencing structure to empower the dynamic help of the ACCs by continuing trickery reports from the ACCs, raising a decision about the judgment making and restoring the isolating order. The $\mathrm{RC}$ registers the data of the area control and dreadful lead settling on a decision about systems identically as their shrewd contracts, what's more gives limits (e.g., enroll, empower and devastate) to deal with these methods. To demonstrate the utilization of the structure, we give a strong examination in an IoT system with one work station, one workstation and two Raspberry Pi single-board PCs, where the ACCs, JC and RC are executed subject to the Ethereum sharp contract stage to accomplish the way control.[14]

The activity based access control (RBAC) structure is an instrument which portrays the passage control rule. As a run of the mill association, an affiliation gives a help of a customer who has a particular occupation it was allotted by a substitute affiliation. 
Such trans-various leveled RBAC is ordinary in $\mathrm{f}$ expert to-face correspondence anyway not in a PC orchestrate, in light of the way that it is difficult to develop both the security that precludes the threatening mime from claiming occupations and the versatility that empowers little relationship to take an intrigue and customers to totally control their own one of a kind employments. This paper, presents a RBAC utilizing sharp contract (RBAC-SC), a stage that makes utilization of Ethereum's talented contract improvement to grasp a trans-different leveled use of occupations. Ethereum is an open blockchain orchestrate that is intended to be secure, adaptable, and flexible, RBACSC system, which is made out of two focal parts, unequivocally, the sharp contract and the test reaction custom, and present an execution examination. A model of the awe inspiring contract is made and passed on Ethereum's Test net blockchain, and the source[15].

Blockchain enhancement and the use of amazing contracts think about computerization of clear affected philosophies between any numbers of social affairs. The Internet of Things (IoT) has seen surprising potential in the earlier decade to adjust our ordinary consistently existences with the inspiration driving robotizing physical systems by solidifying Internet-related contraptions into things. This paper, portray and give a reference plan and execution of a split-virtual machine, AlkylVM, which considers resource constrained IoT devices to interface with blockchain structures[16].This paper proposed, a power-beneficial, long-run correspondence empowered, mechanized, and decentralized IoT and BC-based contamination watching framework is presented, which from one point of view, use the outstanding sort of BC by giving modify safe decentralized and trustable dissipated structures, and a while later afresh, utilizes Lora WAN correspondence custom to give long range and low power drew in correspondence. This assistants in chatting with IoT sensors in condition a long way from sections. Out of the blue, through this work ELC is passed on Loranareas which are a wonderful favored perspective in joining IoT-based applications and BC-based frameworks.[17]

\begin{tabular}{|c|c|c|c|}
\hline $\begin{array}{l}\mathrm{SN} \\
\mathrm{O}\end{array}$ & $\begin{array}{l}\text { AUTHO } \\
\text { RS } \\
\text { NAME }\end{array}$ & $\begin{array}{l}\text { METHODS/TECHNIQUE/ALGO } \\
\text { RITHMS }\end{array}$ & $\begin{array}{l}\text { PROBLEM } \\
\text { IDENTIFIE } \\
\text { D }\end{array}$ \\
\hline 1. & $\begin{array}{l}\text { Chang } \\
\text { Hyung }\end{array}$ & Consenus method, proof-of-stake & $\begin{array}{l}\text { Securing a } \\
\text { blockchain } \\
\text { contracts } \\
\text { And to } \\
\text { create hybrid } \\
\text { blockchain }\end{array}$ \\
\hline 2 & $\begin{array}{l}\text { PRADIP } \\
\text { KUMAR } \\
\text { SHARM } \\
\text { A1 }\end{array}$ & $\begin{array}{lll}\text { distributed } & \text { cloud } & \text { architecture } \\
(\mathrm{SDN}) & & \end{array}$ & $\begin{array}{l}\text { To oversee } \\
\text { gigantic } \\
\text { information } \\
\text { stores, } \\
\text { centralized } \\
\text { server farms } \\
\text { and to give } \\
\text { high } \\
\text { accessibility. }\end{array}$ \\
\hline 4 & $\begin{array}{l}\text { Craig } \\
\text { Wright, } \\
\text { Antonaet } \\
\text { a } \\
\text { Servguie } \\
\text { va }\end{array}$ & Knapsack-based hash functions & $\begin{array}{l}\text { To quicken } \\
\text { the } \\
\text { functionality } \\
\text {, complexity } \\
\text { and } \\
\text { flexibility of } \\
\text { blockchain - } \\
\text { empowered }\end{array}$ \\
\hline
\end{tabular}

\begin{tabular}{|c|c|c|c|}
\hline & & & $\begin{array}{l}\text { administratio } \\
\text { ns. }\end{array}$ \\
\hline 5 & $\begin{array}{l}\text { yi-Hui } \\
\text { Chen, } \\
\text { Shih- } \\
\text { Hsin } \\
\text { chen }\end{array}$ & E-auction mechanism & $\begin{array}{l}\text { to develop } \\
\text { public bid } \\
\text { and sealed } \\
\text { bid. }\end{array}$ \\
\hline 6 & $\begin{array}{l}\text { Ting } \\
\text { Chen }\end{array}$ & BLE-based Devices, Gas Reducer & $\begin{array}{l}\text { To prevent } \\
\text { abuse of } \\
\text { resources }\end{array}$ \\
\hline 7 & $\begin{array}{l}\text { Alexandr } \\
\text { a Covaci }\end{array}$ & Proofs of correct, CCS concepts & $\begin{array}{l}\text { For } \\
\text { blockchain } \\
\text { transaction } \\
\text { validation. }\end{array}$ \\
\hline 8 & $\begin{array}{l}\text { Jianli } \\
\text { Pan }\end{array}$ & $\begin{array}{l}\text { Edge -IOT Framework and } \\
\text { Prototype }\end{array}$ & $\begin{array}{l}\text { To address } \\
\text { the } \\
\text { deficiency of } \\
\text { centralized } \\
\text { cloud } \\
\text { computing. }\end{array}$ \\
\hline 9 & $\begin{array}{l}\text { Kolbeinn } \\
\text { Karlsson }\end{array}$ & $\begin{array}{l}\text { directed acyclic } \quad \text { graph(DAG) } \\
\text { structured block }\end{array}$ & $\begin{array}{l}\text { To provide } \\
\text { power } \\
\text { constrained } \\
\text { network. }\end{array}$ \\
\hline 10 & $\begin{array}{l}\text { Chan } \\
\text { Hyeok } \\
\text { Lee }\end{array}$ & Zero-Knowledge proof & $\begin{array}{l}\text { Measuring } \\
\text { and sharing } \\
\text { the amount } \\
\text { of } \\
\text { electricity. }\end{array}$ \\
\hline 11 & $\begin{array}{l}\text { Carlos } \\
\text { Molina }\end{array}$ & proof of concept & $\begin{array}{l}\text { Proposed } \\
\text { system } \\
\text { interface. }\end{array}$ \\
\hline 12 & $\begin{array}{l}\text { Md } \\
\text { Nazmul } \\
\text { Islam, }\end{array}$ & IoT-enabled telematics devices & $\begin{array}{lr}\text { Proposed } & \text { a } \\
\text { secure } \log \\
\text { storage }\end{array}$ \\
\hline 13 & $\begin{array}{l}\text { JASON } \\
\text { PAUL } \\
\text { CRUZ }\end{array}$ & $\begin{array}{l}\text { different access control contracts } \\
\text { (ACCs), judge contract (JC) and } \\
\text { register contract (RC) }\end{array}$ & $\begin{array}{l}\text { Provides } \\
\text { immutable } \\
\log \text { of } \\
\text { security } \\
\text { policy }\end{array}$ \\
\hline 14 & YUICHI & $\begin{array}{l}\text { RBAC utilizing keen contract } \\
\text { (RBAC-SC), a stage }\end{array}$ & $\begin{array}{l}\text { To present } \\
\text { use case of } \\
\text { integrating } \\
\text { blockchain } \\
\text { and virtual } \\
\text { resources. }\end{array}$ \\
\hline 15 & $\begin{array}{l}\text { Joshua } \\
\text { Ellul, } \\
\text { Gordon } \\
\text { J. Pace }\end{array}$ & split-virtual machine, AlkylVM & $\begin{array}{l}\text { To give } \\
\text { certain } \\
\text { computerizat } \\
\text { ion of } \\
\text { physical } \\
\text { procedures }\end{array}$ \\
\hline 16 & $\begin{array}{l}\text { Sina } \\
\text { Rafati } \\
\text { Niya }\end{array}$ & $\begin{array}{l}\text { a power-productive, long-extend } \\
\text { correspondence empowered, } \\
\text { robotized, and decentralized IoT } \\
\text { and BC-based contamination } \\
\text { checking framework }\end{array}$ & $\begin{array}{l}\text { Represents } \\
\text { the an } \\
\text { enhancement } \\
\text { by enabling } \\
\text { audit } \\
\text { authorization } \\
\text {. }\end{array}$ \\
\hline
\end{tabular}

\section{CONCLUSION}

Utilizing brilliant contracts in such circumstances can result in more viability by lessening the weight. Brilliant contracts are intended to take a shot at condition-based standard (on the off chance that this, that), which will settle the possession issue by exchanging it to the purchaser just when the financial, just as different conditions, are settled upon. I proposed to implement to blockchain with IOT. 
The IoT innovation is being used to interface ordinary gadgets to the web so as to enhance the interconnectivity of the frameworks in with the assistance of sensors. These contraptions can be related with the blockchain structure to screen all of the things and methods insider keen contracts, the blend of blockchain and IoT can be completely mind blowing. Blockchain give us flexible, really passed on disseminated structures and the ability to participate with sidekicks in a trustless, auditable manner. Sharp contracts empower us to robotize complex multi-step shapes. The gadgets in the IoT natural system are the inspirations driving contact with the physical world. Precisely when every one of them are obliged we rouse the opportunity to robotize tedious work frames in new and emerge ways, accomplishing cryptographic undeniable nature, correspondingly as enormous expense and time underpins in the meantime.

We trust that the proceeded with mix of blockchain in the IoT space will cause huge changes over two or three undertakings, achieving new plans of action and having us rethink how existing structures and strategies are figured it out.

\section{REFERENCES}

1. ChangHyung Lee, NakMyoung Sung, Lewis Nkenyereye, and JaeSeung Song "Blockchain Contract: Securing a blockchain Applileid to smart Contracts" 2018 IEEE International Conference on Industrial Internet (ICII)Page s: 467 - 468

2. .PradipKumar Sharma1, Mu-Yen Chen2, And Jong Hyuk Park 1, (Member, IEEE)“A Software Defined Fog Node Based Distributed Blockchain Cloud Architecture For IOT'VOLUME 6, 2018

3. .Craig Wright, Antonaeta Servguieva," Sustainable Blockchain-Enabled Services Smart Contracts",2017 IEEE International Conference on Big Data. Pages: 4255 - 4264 .

4. Yi-Hui Chen, Shih-Hsian chen, "Blockchain Based Smart contracts for Bidding System", IEEE ICASI 2018, IEEE International Conference on Applied System Innovations 2018. ISBN 978-1-5386-4342-6.

5. Ting Chen, Zihao Li "Towards saving money in using smart contracts" 2108 ACM/ IEEE 40thinternational conference on software Engineering: New ideas and Emerging Results. ICSE-NIER'18,MAY 27-JUNE 3,2018.Page s: 81 - 84

6. Alexandra Covaci, Simone Madeo."NECTAR: NonInteractive Smart Contract Protocol using Blockchain Technology"2018 ACM/IEEE Page s: 17 - 24

7. Jianli Pan, Ismail Alqerm, "Edge Chain: An Edge-IoT Framework and Prototype Based on Blockchain and Smart Contracts" IEEE Internet of Things Journal. Page s: $1-1$.

8. Kolbeinn Karlsson, Weitao Jiang, Danny Adams, Edwin Ma" Vegvisir: A Partition-Tolerant Blockchain for the Internet-of-Things "2018 IEEE 38th International Conference on Distributed Computing Systems. Page s: 1150 - 1158

9. Chan Hyeok Lee, Ki-Hyung Kim "Implementation of IoT System using BlockChain with Authentication and Data Protection", Volume 6,

10. Carlos Molina-Jimenez. Ioannis Sfyrakis, Ellis Solaiman, Irene $\mathrm{Ng}$ "Implementation of Smart Contracts Using Hybrid Architectures with On- and Off- Blockchain Components" in 2018 IEEE 8th International Symposium on Cloud and Service Computing (SC2). Page s: 83 - 90
11. Ankush Singla, Elisa Bertino "Blockchain-based PKI solutions for IoT", 2018 IEEE 4th International Conference on Collaboration and Internet Computing"Page s: 9 - 15

12. Md Nazmul Islam, Sandip Kundu "Preserving IoT Privacy in Sharing Economy via Smart contract" 2018 IEEE/ACM Third International Conference on Internetof-Things Design and implementation. International Conference. Page s: 296 - 297

13. 13.JASON PAUL CRUZ, Yuanyu Zhang, "Smart Contract-Based Access Control for the Internet of Things", 2018 IEEE/ACM Third International Conference on Internet-of-Things. Volume: 4 Page s: $1243-1257$.

14. 14.Yuichi "RBAC-SC: Role-based Access Control using Smart Contract" IEEE access, special section on research challenges and opportunities in security and privacy of blockchain technologies, 2018 ieee/acm Third International Conference on Internet-of-Things. Volume: 6Page s: $12240-12251$.

15. Joshua Ellul,Gordon J. Pace, "AlkylVM: A Virtual Machine for Smart Contract Blockchain Connected Internet of Things" 2018 IEEE/ACM Third International Conference on Internet-of-Things.978-1-5386-3662-6.

16. Sina Rafati Niya, Sanjiv S. Jha, Thomas Bocek, Burkhard Stiller "Design and Implementation of an Automated and Decentralized Pollution Monitoring System with Blockchain, Smart Contracts, and LoRaWAN"

17. Dr.D.Akila, Dr.C. Jayakumar, "Acquiring Evolving Semantic Relationships for WordNet to Enhance Information Retrieval", International Journal of Engineering and Technology, Volume 6, November 5, pp. 2115-2128, 2014.

18. Dr. D.Akila,S.Sathya, Dr.G.Suseendran, "Survey on Query Expansion Techniques in Word Net Application", Journal of Advanced Research in Dynamical and Control Systems, Vol.10(4), pp.119-124, 2018. 